\title{
$\mathrm{CVM}$ 을 활용한 남북·대륙철도 연결에 따른 지불의사액 산정 연구
}

김주영 ${ }^{1}$ - 진장원 ${ }^{2 *}$

${ }^{1}$ 한국교통대학교 교통정책학과 교수, ${ }^{2}$ 한국교통대학교 교통정책학과 교수

\section{Estimation of Willingness to Pay by Trans-Korean Railway Connection Using CVM}

\author{
KIM, Jooyoung ${ }^{1}$ (D) $\cdot$ JIN, Jangwon ${ }^{2 *}$ D \\ ${ }^{1}$ Professor, Department of Transportation Planning \& Management, Korea National University of \\ Transportation, Gyeonggi 16106, Korea \\ ${ }^{2}$ Professor, Department of Transportation Planning \& Management, Korea National University of \\ Transportation, Gyeonggi 16106, Korea \\ *Corresponding author: jangwon@ut.ac.kr
}

J. Korean Soc. Transp.

Vol.38, No.3, pp.167-175, June 2020

https://doi.org/10.7470/jkst.2020.38.3.167

pISSN : 1229-1366

elSSN : 2234-4217

\section{ARTICLE HISTORY}

Received: 30 December 2019

Revised: 3 February 2020

Accepted: 12 May 2020

Copyright (C)

Korean Society of Transportation

This is an Open-Access article distributed under the terms of the Creative Commons Attribution Non-Commercial License

(http://creativecommons.org/licenses/by-nc/3.0) which permits unrestricted non-commercial use distribution, and reproduction in any medium, provided the original work is properly cited.

\begin{abstract}
Recent construction of Trans-Korean Railway result in travel time reduction and also production and employment increase during construction phase. Those direct benefits are estimable using existing development methodology. But indirect benefits such as community development and economy, social culture are hard to be quantified. Therefore, this study estimated the economic benefits in terms of regional economy, development, and socio-cultural aspects of the operation of Trans-Korean Railway by using CVM (Contingent Valuation Method). It surveyed 545 adults over 20 years old, and estimated willingness to pay on usage of Trans-Korean Railway. As a result, respondents were willing to pay 13,824 won per household in residence tax. Moreover, total annual economic benefit regional economic and social culture due to Trans-Korean Railway is estimated to be 291.9 billion won.
\end{abstract}

Keywords: contingent valuation method, double-bounded dichotomous choice, logistic regression model, trans-Korean railway, willingness to pay

\section{초록}

최근 추진 중인 남북·대륙철도는 건설 단계에서 생산·고용이 증대되고, 운행단계에서 통행 시간 단축으로 인한 직접적인 편익은 기존 방법을 통해 추정이 가능하다. 그러나 지역개발, 지 역경제, 사회문화적인 간접적인 편익은 계량화하기 어려운 측면이 있다. 이에 본 연구에서는 조 건부가치측정법을 활용하여 남북·대륙철도 운영으로 인한 지역 경제·개발, 사회문화 측면의 경제적 편익을 추정하였다. 20대 이상 성인 545명을 대상으로 설문조사를 시행하여 남북·대륙 철도 시행에 대한 사용가치 즉, 지불의사금액(Willingness to Pay)을 추정하였다. 분석 결과, 가 구당 13,824 원을 주민세로 지불할 의사가 있는 것으로 분석되었고, 남북·대륙철도로 인한 지 역경제·사회문화 측면의 연간 총 경제적 편익은 2,719 억 원인 것으로 추정되었다.

주요어: 조건부가치측정법, 이중양분선택법, 로지스틱회귀모형, 남북·대륙철도, 지불의사금액 
서론

\section{1. 연구의 배경 및 목적}

해방 후 현재 우리나라는 열강에 의해 남북이 분단되었고, 육로를 통해 직접적인 대륙진출 통로가 막혀 있는 현실 이다. 그로 인해 한국의 국가 간 교통·물류체계는 항공 및 해상 운송 위주로 편성될 수밖에 없었다. 그 결과, 한국은 유라시아 대륙에 위치한 거대한 시장인 중국, 러시아, 몽골과 같은 국가들과의 협력에 있어서 지정학적 이점을 제대 로 활용할 수 없었다. 그러나 최근 남북한 화해와 협력의 시대를 여는 남북철도 연결공사가 시작됨으로써 한국이 동 북아 물류·교통의 중심지로 부상할 수 있는 가능성을 얻게 되었다.

남북한 간의 철도연결 사업은 분단된 국토를 연결하는 상징성과 함께 기존의 남북관계를 한 차원 더 높이고, 새로 운 동북아 협력시대를 여는 중요한 정책과제 가운데 하나이다. 유럽철도망이 교통망으로써의 역할 뿐만 아니라 유 럽의 경제·사회·문화를 통합하여 유럽연합(EU)의 결성을 앞당겼듯이, 현재 진행 중인 남북·대륙철도 연결사업은 동북아지역에 협력 인프라를 마련함으로써 ‘평화와 번영의 동북아시대’를 선도할 수 있는 핵심사업이 될 것이다. 또 한, 동북아를 통합하는 국제 승객철도망과 유라시아 대륙을 연결하는 국제 화물철도망으로 발전하는 계기를 마련할 수 있을 것이다 $(\mathrm{Na}, 2006)$.

남북·대륙철도 건설· 운영으로 인해 사회· 경제· 문화 측면에서 다양한 편익이 발생하는데, 생산적이고 효율적 인 남북·대륙철도 건설·운영을 위해서는 이러한 편익을 정량적으로 파악하고 분석하는 것이 중요하다. 남북·대륙 철도 건설로 인해 발생하는 생산·고용 증대 효과는 산업연관분석이 가능하며, 철도 여객·물류 수송으로 인한 교통 측면 효과는 교통모형 기반으로 분석이 가능하다. 이에 반해 남북·대륙철도로 인해 발생하는 지역경제 활성화, 역 세권 등 도시지역 개발, 한반도 평화 기여에 따른 사회문화 측면 등 효과는 다양한 방법으로 정량적으로 분석할 수 있으나, 많은 연구가 이루어지지 않았다. 따라서 본 연구에서는 계량화된 방법을 이용하여 남북· 대륙철도 운영으로 인한 지역 경제·개발, 사회문화 측면의 편익, 다시 말해서 사용가치인 지불의사금액(Willingness to Pay)을 추정하 고, 지불의사금액에 영향을 미치는 요인을 분석함으로써 남북·대륙철도 건설·운영의 기초자료로 활용하고자 하는 데 목적이 있다.

\section{2. 연구의 내용 및 방법}

남북- 대륙철도의 경제적 가치를 추정하기 위하여 주민세를 활용하였으며, 소득이 있는 가구를 조사 대상으로 설정 하였다. 모집단은 대한민국 국민을 대상으로 고속버스 터미널과 화물터미널에서 1:1 직접 면접조사를 수행하였다.

표본수의 경우, 표준정규분포의 신뢰구간과 추정오차에 따른 표본 수에 따라 신뢰수준 $99 \%$, 허용오차 $5 \%$ 의 기 준에 의거하여 최종 유효표본수는 550부로 결정하였으며, 조사 시 결측 자료를 감안하여 최종적으로 결정한 조사 표본 수는 545부로 설정하였다.

본 연구에서 남북·대륙철도의 경제적 가치는 이용자의 사용가치로 정의하였고, 사용가치는 남북·대륙철도 시행 에 따른 연간 주민세를 통한 지불의사액으로 설정하였다. 지불의사액 및 결정요인 분석을 위한 방법으로 조건부가 치추정법(Contingent Valuation Method, CVM)을 이용하였다.

\section{선행연구 고찰}

\section{1. 공공재의 가치측정법}

공공재의 공급 수준 변화에 대한 편익을 추정하는 방법은 매우 다양하며 공공재 공급 수준 증가에 대한 지불의사 를 도출하는 접근방법은 크게 시장적 방법(market methods), 현시선호방법(revealed preference methods), 진술선 호방법(stated preference methods) 세 가지로 구분할 수 있다. 
Revealed preference 방식은 시장에서 거래되는 가격을 토대로 가치를 추정하는 방식이며, Stated preference 방 식은 시장에서 거래되지 않는 재화나 서비스의 가치를 추정하기 위해 가상 시장을 상정한 뒤, 설문조사를 통해 지불 용의액을 추정하여 환경 가치를 구하는 방식으로 Stated preference 방식에서 가장 널리 쓰이는 방법은 조건부가치 추정법이 있다.

조건부가치측정법은 설문지 디자인의 유연성으로 인해 여러 종류의 비시장재 가치평가에 사용할 수 있는 장점이 있지만, 사람들의 실제 의사 결정으로 드러난 '현시된 선호' (Revealed preference)에 바탕을 두지 않고, 가상적인 상 황에서 소비자들의 지불의도에 기초한 '표현된 신호' (Stated preference)에 의존한다는 문제가 있다. 이로 인해 소비 자들은 자신이 지불하겠다고 표현한 대로 행동하지 않을 가능성이 상존하고, 결과적으로 조건부가치측정법 추정치 가 실제 지불의사액보다 과대평가 혹은 과소평가될 위험이 존재한다(Brent, 1995).

\section{CVM을 활용한 공공재의 가치측정법 사례}

Ryu et al.(2016)은 수도권지역을 운행하는 광역버스를 대상으로 차내혼잡도 완화에 따른 지불의사액을 추정하였 다. 설문조사를 통해서 992개의 유효표본이 얻어졌으며 연령, 소득수준, 버스탑승시간, 통행목적, 혼잡도 등을 설명 변수로, 광역버스 차내혼잡도 완화에 대한 추가지불의사액을 종속변수로 하는 Tobit모형을 추정하였다. 수도권 지 역에서 광역버스 좌석제를 시행할 경우 일평균 약 61 백만 원, 연간 약 147 억 원의 편익이 발생할 것으로 추정되었다.

Lee and $\operatorname{Han}$ (2016)은 계량화된 방법으로 공공자전거시스템의 사용가치인 지불의사금액을 추정하고, 지불의사 금액에 영향을 미치는 결정요인을 분석하였다. 대전시의 공공자전거시스템인 타슈를 분석대상으로 하여 현장 설문 조사를 통하여 자료를 수집하였으며, 조건부가치측정법을 활용하였다. 지불의사금액에 영향을 미치는 요인들은 자 전거 이용횟수는 양 $(+)$ 의 영향, 자동차보유대수 및 연령은 음(-)의 영향 그리고, 성별과 소득 등은 관련성이 나타나 지 않았다. 또한, 타슈의 연간 경제적 편익은 최소 499.3억 원에서 최대 636.1억 원에 달하는 것으로 분석되었다.

$\mathrm{Cho(2013)는} \mathrm{도로특성(도시부/지방부)} \mathrm{및} \mathrm{차량} \mathrm{밀도(차간거리)에} \mathrm{따른} \mathrm{이용자의} \mathrm{지불의사액을} \mathrm{CVM} \mathrm{방법} \mathrm{중}$ 이중양분선택형(double-bounded dichotomous choice)질문법을 활용하여 조사하였으며, 설문조사 결과를 로짓 모형에 적용하여 운전쾌적성 가치를 도출하였다.

\section{3. 남북대륙철도 경제적 효과 분석 사례}

Lee(2018)는 경의선을 중심으로 한 철도를 통한 환황해 경제벨트를 구축함으로써 발생하는 관광수요에 따른 경 제적 효과를 추정하였다. 남북철도 개통에 따라 발생하는 평양, 개성, 신의주 등의 관광객이 30 년간 총 6,841 만 명 (연평균 228만 명)으로 추정하였고, 향후 30년간 관광객 만족도 편익이 20.6조원(현재가치 9.5조원)이 발생할 것이 라 분석하였다. 또한 이동편의성 개선으로 인한 비용저감 효과는 66.8조원(현재가치 30.8 조원)이 발생할 것이라 추 정하였다.

\section{설문조사 계획 및 분석방법}

본 연구는 남북- 대륙철도 연결사업을 평가 대상재로 선정하고, 철도연결에 따른 지역개발, 교류기회의 제공, 생 활권 확대, 통일에 대한 준비로써의 이타적가치, 유산가치, 존재가치를 측정하였다. 조건부가치측정법이 실제 시장 에서 거래되지 않는 비시장재화에 대해 가상시장을 설정하여 응답자들이 실제로 물건을 구매하는 것처럼 생각할 수 있도록 해야 하기 때문에 응답자 정보제공이 중요하다.

"남북철도 연결로 인해 지역개발, 생활권 확대를 통한 남북 교류확대 및 통일에 대한 사전 준비과정으로써 남북 대륙철도를 연결한다면 얼마를 지불할 의향이 있는가” 라는 시나리오를 구성하였다. 개선 항목으로는 역세권개발 및 지방인구정착을 통한 지역개발, 유라시아 대륙과의 생활권 확대 및 교류증진을 통한 생활문화 개선, 분단된 국토 
연결 및 남북관계 개선을 통한 통일에 대한 준비 등 이타적 가치와 유산가치, 존재가치에 대하여 응답자에게 설문조 사 전에 충분히 정보를 제공하였다.

응답자의 지불수단으로는 남북대륙철도 연결 사업이 제공하는 공익적 기능의 시행을 위한 재원확보의 가능성, 응답자의 친숙성, 평가될 대상과의 연계성을 종합적으로 고려하여 세금(주민세)을 지불수단으로 선택하여 신뢰성 을 높일 수 있도록 하였다. 또한, 지불의지액의 제시 금액을 설계하기 위하여 Alebrini(1995)의 분위 수 설계 방식에 따라 지불의지액 누적 확률이 $20 \%, 40 \%, 60 \%, 80 \%$ 되는 금액을 제시 금액으로 설정하였다. 이를 위하여 본 설문 조사의 20\%(100부)에 해당하는 예비 설문조사를 실시하였으며, 이때 일반적으로 지불의사액의 제시 금액 설계시 단일경계모형에서는 경험법칙에 의하여 15 분위수와 85 분위수 이내의 값들을 제거하였다.

지불유도방법으로는 크게 개방형 질문법과 폐쇄형 질문법이 존재하며, 폐쇄형 질문법은 경매법, 양분선택법, 이 중양분선택법으로 구분할 수 있다. 본 연구에서는 응답자가 대답하기 용이하여 응답률이 높고, 출발점 편의나 설문 조사원 편의에 따른 영향이 적으며, 비합리적 지불의사가 발생할 가능성이 비교적 적은 이중양분선택형(DoubleBounded Approach)을 선정하였다. 만약 $n$ 원의 세금을 지불할 의사가 있는지 물어보고, 지불의사가 있다면 $2 n$ 원의 세금을 지불할 의사가 있는지 물어보며, 지불의사가 없다면 $\mathrm{n} / 2$ 원의 세금을 지불할 의사가 있는지 물어본다. $2 n$ 원 의 세금을 지불할 의사가 있다면, 최대 지불가능한도가 얼마인지 물어보고, 만약 $2 n$ 원의 세금을 지불할 의사가 없으 면 적어도 지불가능한 한도가 얼마인지 물어본다. $n / 2$ 원의 세금을 지불할 의사가 있다면 어느 범위까지 지불의사가 있는지 물어보고, 이마저도 세금을 지불할 의사가 없다면, 이 개선사업에 돈을 전혀 쓰지 않을 것인지 물어보는 과정 을 거친다. 이러한 과정은 Figure 1과 같다.

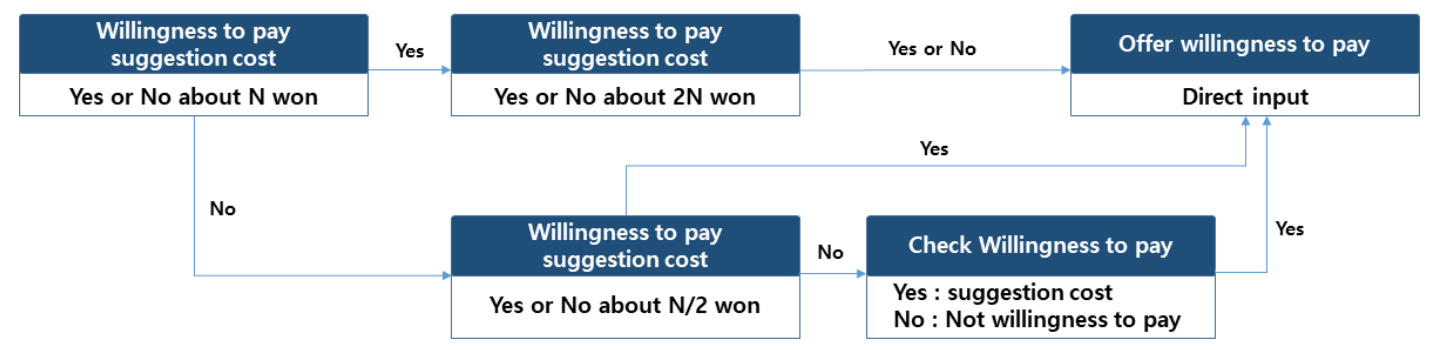

Figure 1. Flowchart of checking willingness to pay using CVM

\section{지불의사금액 추정 방법 및 결과}

\section{1. 모형 정립}

본 조사에서는 제시된 금액(반응변수)에 대해 '예(I=1)'와 '아니오(I=0)'의 응답에 대하여 0과 1에 대한 분석이 가 능한 Logistic Regression Model 중 하나인 Binary Logit Model을 이용하였다.

$$
\operatorname{logit}[\pi]=\log \left(\frac{\pi}{1-\pi}\right)=\alpha+\beta_{1} x_{1}+\cdots+\beta_{i} x_{i}, n=1,2,3, \cdots, i
$$

모든 설명변수는 명목변수와 순서형 변수로 구분하였다. 물류 협력 필요성, 생활권 확대, 철도공동체 실현, 연령은 순서형 예측변수이므로 순서형 예측변수를 양적으로 취급하여 간단한 모형으로 구성하였다. 위의 범주들에 단조성 을 만족하는 범주점수를 부여함으로써 선형효과를 갖도록 하였다. 또한, 화물종사자 여부는 변수의 종류 간에 서로 연관성이 없는 명목변수이므로, 이를 고려하여 통계적 모형을 구성하였다. 본 설문조사에서 쓰일 모형은 Equation 2와 같다. 


$$
\operatorname{logit}[\pi]=\log \left(\frac{\pi}{1-\pi}\right)=\alpha+\beta_{1} x_{1}+\beta_{2} x_{2}+\beta_{3} x_{3}+\beta_{4} x_{4}+\beta_{5} x_{5}
$$

위 모형의 X의 효과에 관한 유의성을 검정하기 위해 가설을 $H_{0}: \beta=0$ Vs. $H_{1}: \beta \neq 0$ 으로 설정하였다. 이 귀무가 설을 검정하기 위한 검정통계량을 Equation 3과 같다.

$$
z=\frac{\hat{\beta}}{A S E}
$$

이 검정통계량의 분포는 대표본인 경우 $\beta=0$ 이면 표준정규분포에 근사하다. 위의 검정통계량을 제곱하면 자유 도 1 인 카이제곱분포를 갖는 왈드통계량이 도출된다.

$$
z^{2}=\left(\frac{\hat{\beta}}{A S E}\right)^{2}
$$

왈드 통계량과 더불어 Log Likelihood Ratio도 도출되는데, $H_{0}: \beta=0$ 일 때 최대로그우도를 $L_{0}, \beta$ 에 대한 무제한 의 가정 하에서 구해진 최대로그우도를 $L_{1}$ 이라 할 때, 우도비 검정통계량을 $-2\left(L_{0}-L_{1}\right)$ 으로 제시한다. 표본크기가 클 경우 $H_{0}$ 하에서 자유도 1 인 카이제곱 근사분포를 따른다.

\section{2. 모형 추정}

\section{1) 기초통계량 분석}

조사는 고속버스 터미널과 화물터미널에서 1:1 면접조사로 550명을 대상으로 수행되었으며, 검수를 통해 무응 답 등을 제외한 545 부가 유효표본으로 선정되었다. Table 1에서와 같이 성별, 연령대별, 소득별 분포를 토대로 조사 표본이 비교적 랜덤하게 추출되었다는 것을 확인할 수 있다.

\section{Table 1. Frequency analysis}

\begin{tabular}{llr}
\hline & & Frequency \\
\hline Gender & Male & 306 \\
& Female & 239 \\
Householder status & Householder & 195 \\
Job & Partner of householder & 350 \\
& Cargo worker & 75 \\
Dispersed families status & Not cargo worker & 470 \\
& Yes & 31 \\
Age & No & 514 \\
& $20-29$ & 235 \\
& $30-39$ & 84 \\
Income & $40-49$ & 83 \\
& $50-59$ & 94 \\
& $60-$ & 49 \\
& Less than 1 million won & 56 \\
& Between 1 million won and 2 million won & 35 \\
& Between 2 million won and 3 million won & 101 \\
& Between 3 million won and 4 million won & 120 \\
& Between 4 million won and 5 million won & 91 \\
& Between 5 million won and 10 million won & 106 \\
& More than 10 million won & 36 \\
\hline
\end{tabular}




\section{2) 변수 선정}

CVM 연구의 유효성은 지불의사금액이 경제이론이나 다른 연구 및 문헌에서 중요하다고 제시하는 변수들에 영 향을 받고, 이 변수들의 계수가 예상되는 부호를 가지고 있거나 통계적으로 유의한 것인가를 살펴봄으로써 판단할 수 있다. 산점도와 상관행렬로 설문조사 항목에서의 변수들을 분석한 결과, 물류협력의 필요성(Q1), 경제성장의 돌 파구(Q3), 생활권 확대(Q4), 남북 교류기회 제공(Q5), 철도공동체 실현(Q6), 화물 종사자(Q9), 연령(Q12) 등 7개 의 설명변수가 상관성이 있는 것으로 판단되었다. 반면, 이산가족 여부는 남북·대륙철도의 지역경제·사회문화적 편익과 상관성이 높지 않은 것으로 나타났는데, 이는 이산가족 표본이 31개로 적고, 이산가족 응답자와 이산가족이 아닌 응답자가 서로 유사한 응답을 하였기 때문인 것으로 사료된다.

변수 선정은 상관행렬을 분석한 결과 지불의사를 표현한 응답자와의 상관관계 계수가 0.2 이상인 경우를 우선 선 정하였고 단순 후진소거법의 결과와 우선 비교하였다. 모형의 신뢰성을 유지하며 설명력 있는 변수를 선택하기 위해 우선 선정된 변수간의 최적 조합을 비교하였고, 그 중 Likelihood Ratio의 p-value와 Wald chi-square의 p-value 가 낮으면서 설명 가능한 4개 이상의 변수를 고려한 모형을 Table 2와 같이 선정하였다.

본 연구에는 후진소거법의 결과와 CVM 연구의 유효한 변수들을 참고하여 물류협력의 필요성(Q1), 생활권 확대 $(\mathrm{Q} 4)$, 철도공동체 실현(Q6), 화물 종사자 $(\mathrm{Q} 9)$, 연령 $(\mathrm{Q} 12)$ 의 5가지 변수를 최종적인 변수로 선정하였다. 최종변수 로 선정된 변수의 상관행렬은 Table 3과 같다. 여기서, "Yes" 항목은 지불의사가 있다고 대답한 응답을 "1"로 표시 한 변수이며, 모든 변수의 상관계수가 0.2 이상인 것을 알 수 있다.

Table 2. Definition of variable

\begin{tabular}{llcc}
\hline \multicolumn{1}{c}{ Variable } & \multicolumn{1}{c}{ Description } & Ave. & s.d. \\
\hline $\begin{array}{l}\text { Necessity of logistics } \\
\text { cooperation }\left(X_{1}\right)\end{array}$ & Score of 1-5 step, the higher the score, the more TKR is needed & 3.46 & 1.20 \\
$\begin{array}{l}\text { Expansion of life zone } \\
\left(X_{2}\right)\end{array}$ & $\begin{array}{l}\text { Score of 1-5 step, the higher the score, the more life zone (Eurasia) } \\
\text { is expanded }\end{array}$ & 3.49 \\
$\begin{array}{l}\text { Realization of railway } \\
\text { community }\left(X_{3}\right)\end{array}$ & $\begin{array}{l}\text { Score of 1-5 step, the higher the score, the more railway community } \\
\text { is realized }\end{array}$ & 3.37 & 1.06 \\
Age $\left(X_{4}\right)$ & 20's $X_{4}=1,30$ 's $X_{4}=2,40$ 's $X_{4}=3,50$ 's $X_{4}=4,60$ 's or older $X_{4}=5$ & 2.34 & 1.40 \\
Cargo worker $\left(X_{5}\right)$ & A cargo worker $X_{5}=1$, Not $X_{5}=-1$ & -0.725 & 0.69 \\
\hline
\end{tabular}

Table 3. Correlation matrix of variable

\begin{tabular}{lllllll}
\hline Variable & $X_{1}$ & $X_{2}$ & $X_{3}$ & Yes & \multicolumn{1}{c}{$X_{4}$} & \multicolumn{1}{c}{$X_{5}$} \\
\hline$X_{1}$ & 1.00 & 0.43 & 0.43 & 0.40 & -0.31 & -0.14 \\
$X_{2}$ & 0.43 & 1.00 & 0.44 & 0.56 & -0.20 & -0.29 \\
$X_{3}$ & 0.43 & 0.44 & 1.00 & 0.60 & -0.20 & -0.29 \\
Yes & 0.40 & 0.56 & 0.60 & 1.00 & -0.32 & -0.25 \\
$X_{4}$ & -0.31 & -0.20 & -0.20 & -0.32 & 1.00 & 0.12 \\
$X_{5}$ & -0.14 & -0.29 & -0.29 & -0.25 & 0.12 & 1.00 \\
\hline
\end{tabular}

\section{3) 모형 추정 결과}

남북·대륙철도의 지역경제 · 사회문화 측면의 지불의사액 모형은 Table 4와 같이 Equation 5 로 추정되었다.

$$
\operatorname{logit}[y]=-3.435+0.644 X_{1}+0.340 X_{2}+0.337 X_{3}-0.276 X_{4}-0.360 X_{5}
$$


Table 4. Estimation results on model

\begin{tabular}{|c|c|c|c|c|c|c|c|}
\hline Variable & Estimated & value & Standard error (ASE) & Wald & Chi-square & $+/-$ & $\mathrm{p}$-value \\
\hline Intercept & - & 3.435 & 0.859 & 2 & 15.991 & $(-)$ & $<.01$ \\
\hline $\begin{array}{l}\text { Necessity of logistic } \\
\text { cooperation }\left(X_{1}\right)\end{array}$ & & 0.644 & 0.135 & 2 & 22.756 & $(+)$ & $<.01$ \\
\hline $\begin{array}{l}\text { Expansion of life zone } \\
\left(X_{2}\right)\end{array}$ & & 0.340 & 0.180 & & 3.568 & $(+)$ & 0.06 \\
\hline $\begin{array}{l}\text { Realization of railway } \\
\text { community }\left(X_{3}\right)\end{array}$ & & 0.337 & 0.161 & & 4.381 & $(+)$ & 0.04 \\
\hline Age $\left(X_{4}\right)$ & - & 0.276 & 0.086 & 1 & 10.300 & $(-)$ & $<.01$ \\
\hline Cargo worker $\left(X_{5}\right)$ & - & 0.360 & 0.161 & & 5.000 & $(+)$ & 0.03 \\
\hline LR Chi-square & \multicolumn{7}{|c|}{183.01} \\
\hline LR p-value & \multicolumn{7}{|c|}{$<.01$} \\
\hline Wald Chi-square & \multicolumn{7}{|c|}{116.82} \\
\hline Wald p-value & \multicolumn{7}{|c|}{$<.01$} \\
\hline df & \multicolumn{7}{|c|}{4} \\
\hline
\end{tabular}

다중로지스틱회귀모형의 적합도는 Wald Chi-square 값을 따르는데, 이 통계량의 값은 자유도가 4인 183.01이 고 $\mathrm{p}$-value는 〈.001으로 추정된 모형이 적합하다는 것을 의미한다. $\mathrm{p}$-value값으로 추정한 결과 사업필요성, 생활 권 확대, 철도공동체 실현, 연령, 화물종사자가 각각 $95 \%$ 의 신뢰구간에서 $H_{0}: \beta=0$ 임을 기각한다.

사업의 필요성, 생활권 확대, 철도공동체 실현의 경우, 지불의사와 양(+)의 관계를 가지는 것으로 추정되었으며, 이는 사업이 필요하다고 느끼고, 생활권 확대와 철도공동체 실현에 도움을 준다고 생각할수록 지불의사가 높다는 것을 의미하며, 논리적으로 부합한다고 볼 수 있다. 또한, 연령의 경우 지불의사와 음(-)의 관계를 갖고 있으며, 상대 적으로 연령이 낮을수록 지불의사를 가진 사람이 많음을 나타낸다. 이는 상대적으로 진보적인 젊은 세대일수록 남 북대륙철도 사업에 보다 긍정적으로 생각한다고 보기 때문인 것으로 사료된다.

화물종사자의 경우 지불의사와 음(-)의 관계를 갖고 있으며, 이는 상대적으로 화물종사자가 아닐수록 지불의사 가 더 높음을 나타낸다. 이는 남북대륙철도는 철도물류와 연계되어 있어 공로물류와 경쟁관계에 있는 철도 수단에 화물 종사자의 인식이 좋지 않기 때문인 것으로 판단된다.

\section{4) 지불의사액(WTP) 추정}

지불의사함수 추정결과에 따라 남북·대륙철도의 지불의사액은 Equation 5 를 통해 추정할 수 있다. 545 명의 표 본에 대하여 설명 변수 각각의 값을 회귀식에 대입해야 지불확률을 얻을 수 있다. 이 때, logit임을 고려하여 실제 확 률은 Equation 6에서 y에 관한 식으로 풀어야 설명 변수에 따른 지불의사 추정치가 도출된다.

$$
\operatorname{logit}[y]=\log \left(\frac{y}{1-y}\right)-3.435+0.644 X_{1}+0.340 X_{2}+0.337 X_{3}-0.276 X_{4}-0.360 X_{5}
$$

최종 지불 가능금액을 각 표본에 곱해주어 지불의사금액을 추정할 수 있고, 전체 표본 집단에 대한 평균지불의사 금액을 추정할 수 있다. 그러나 연령별 표본비율을 검토한 결과, 20 대가 235 명으로 전체 표본 545명 중 $43.1 \%$ 를 차 지하고 있어 이에 대한 보정이 불가피하다. 연령별 지불의사금액 조사 결과는 Figure 2 와 같다. 20 대의 경우, 13,130 원으로 조사되었으며, 50대가 13,002원으로 가장 낮았으며 60대 이상이 19,597원으로 가장 높은 것으로 조사되 었다. 


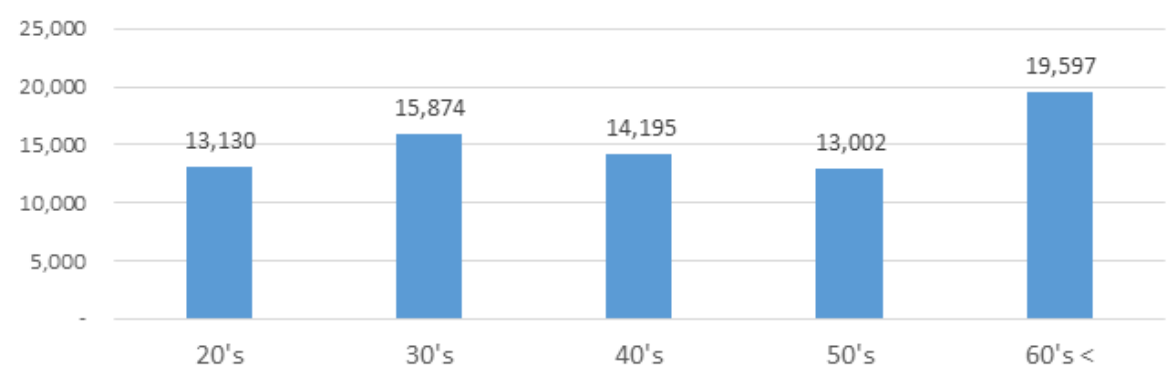

Figure 2. Age-specific average of WTP

표본 비율에 대한 보정을 위하여 Outcome-based sampling 방법을 활용하여 연령별 가중치를 적용하였다. 특정 선택모형의 지불의사금액의 상수에 가중치를 적용하는 방법으로 일반적인 방법으로는 수단 선택 모형에서 사용되 는 $\log \left(S F_{i} / P F_{i}\right)$ 를 상수에 대입하여 반영하였다. 여기서, SF는 특정 집단의 개수, 즉 20대 표본 수, 이외의 경우에는 이외의 표본 수를 뜻하고, $\mathrm{PF}$ 는 모집단의 개수를 의미한다. 본 연구에서 사용된 모형은 이항 로지스틱 회귀모형이 고, 위 분포의 특성은 이항 로짓모형과의 역함수 관계를 가지고 있으므로 유사하게 적용할 수 있다.

가중치를 적용하여 보정한 연평균 지불의사금액(WTP) 분석 결과, 가구당 추가적으로 주민세를 납부할 수 있다 고 한 금액은 $13,824.5$ 원으로 추정되었다. 2019년 기준 인구와 가구 수를 고려할 때, 남북·대륙철도로 인한 지역경 제· 사회문화 측면의 연간 총 경제적 편익은 Table 5와 같이 2,719억 원(2019년 기준)인 것으로 추정되었다. 이는 향후 30년간으로 볼 때, 8.2조원으로 추정되었으며, 2018년 한국교통연구원에서 발표한 경의선 현대화에 따른 관 광객 만족도 편익 9.5 조원과 유사하게 산출되었다.

Table 5. Estimation of gross benefit

\begin{tabular}{lc}
\hline \multicolumn{1}{c}{ Variable } & Estimated value \\
\hline Population & $51,709,098$ \\
Number of households & $19,673,875$ \\
Annual gross benefit & 271,981 (million won) \\
\hline
\end{tabular}

\section{결론}

남북철도의 건설과 대륙철도와의 연결로 인한 제 파급효과는 막대한 사업규모로 인해 건설단계에서부터 많은 영 향을 미칠 것으로 보인다. 남북· 대륙철도 건설로 인해 예상되는 사회경제적 편익항목은 건설단계에서 발생하는 효 과와 운행단계에서 발생하는 효과로 구분할 수 있다. 본 연구는 운행단계에서의 간접적인 파급효과를 공공재의 효 과측정방법의 하나인 조건부가치측정법(CVM)으로 지역경제 개발, 사회문화적 측면의 편익을 산출했다는데에 의 의가 있다. 설문조사 응답자의 주민세 지불의사액을 추정함으로써 남북·대륙철도 운행으로 인해 지역경제·사회문 화적 경제적 파급효과를 추정한 결과, 가구당 약 13,824 원의 주민세를 납부할 의사가 있는 것으로 추정되었으며, 국 내 인구 및 가구 수를 고려할 때 약 2,719억 원의 편익이 발생하는 것으로 추정되었다. 또한, 사업의 필요성, 생활권 확대, 철도공동체 실현과 양(+)의 영향관계를 갖으며, 연령대가 높을수록 지불의사가 낮으며, 화물종사자가 비종사 자에 비해 음(-)의 영향관계를 가지는 것으로 나타났다. 이를 통해 한반도 평화와 남북한과 유라시아 대륙과의 지역 공동체 형성에 긍정적인 인식을 가지고 있으나, 연령이 높을수록 남북·대륙철도에 부정적인 인식을 가지는 것을 간 접적으로 확인할 수 있었다.

따라서 본 연구 결과를 바탕으로 볼 때, 동북아지역 간 지역공동체 형성의 모티브가 될 수 있는 남북·대륙철도 구 축을 가속화할 필요가 있다고 사료된다. 또한, 남북·대륙철도 운영의 효과가 극대화될 수 있도록 정치·사회적 노력 
이 필요하며, 남북·대륙철도로 인해 국민들에게 파생될 수 있는 많은 효과에 대한 국가적인 홍보전략 수립이 필요 할 것으로 보인다.

본 연구는 비시장재의 가치측정방법론으로서 조건부가치측정법을 활용해서 남북·대륙철도 운행단계에서의 간 접적인 편익을 추정하였다. 그러나 조건부가치측정법은 가상상황에 대하여 소비자의 선택에 의거한 결과이기 때문 에 현실과 괴리가 있는 결과가 도출될 수 있다. 특히, 설문조사 응답자는 남북·대륙철도가 공공사업으로 이루어질 것이라는 기대감에 실제 선호도보다 높은 지불의사를 적어내는 전략적 편의(Strategic Bias)가 발생할 수 있다. 이러 한 문제를 조건부가치측정법으로는 근본적으로 해결할 수 없는 한계를 가지고 있다. 또한, 남북·대륙철도는 여객뿐 만 아니라 동북아 물류 연계 측면에서 보다 많은 경제적 편익이 발생할 것으로 예상된다. 그러나 본 연구는 화물 종 사자도 포함되어 있지만, 대부분 일반인을 대상으로 설문조사하였기 때문에 물류보다 여객수송에 치중된 경제적 편 익이 도출되었다고 볼 수 있다. 따라서 향후 남북· 대륙철도의 물류, 여객 수송별 간접적인 경제적 편익을 추정할 수 있는 추가적인 연구가 필요할 것으로 사료된다.

\section{Funding}

This work was supported by Korea National University of Transportation in 2019.

\section{ORCID}

KIM, Jooyoung (1) http://orcid.org/0000-0003-4675-3895

JIN, Jangwon (10 http://orcid.org/0000-0002-5538-393X

\section{References}

Alebrini A. (1995), Efficiency vs. Bias of Willingness to Pay Estimates: Bivariate and Interval-Data Models, 29(2), J. of Environmental Economics and Management, 169-181.

Brent Robert J. (1995), Applied Cost-Benefit Analysis, Edward Elgar Press.

Cho H. S. (2013), A Study on the Benefit of Driving Amenity Based on Highway Density, J. Korean Soc. Transp., 31(5), Korean Society of Transportation, 48-59.

Lee J. H. (2018), The economic effects of modernization of Gyeongui Line, The International Seminar.

Lee J. Y., Han S. Y. (2016), Economic Valuation and Determinant Factors of Bicycle Sharing System in Daejeon City, J. Korean Soc. Transp., 34(1), Korean Society of Transportation, 43-54.

Na H. S. (2006), Reconnecting the Trans-Korean Railway and Future Aspirations of Northwest Asia Railway Network, Korean Society for Railway, 48-55.

Ryu S. K., Han S. W., You J. S. (2016), Measuring Social Benefit of Mitigation of In-Vehicle Congestion Level in Intercity Buses, J. Korean Soc. Transp., 34(6), Korean Society of Transportation, 523-534. 